\title{
Cap-assisted colonoscopy: a meta-analysis of high-quality randomized controlled trials
}

\section{(ㄷ)(1) $\odot$}

\author{
Authors \\ Institutions \\ 1 Department of Internal Medicine, The University of \\ Kansas Medical Center, Kansas City, Kansas, United \\ States \\ 2 Department of Gastroenterology, The University of \\ Kansas Medical Center, Kansas City, Kansas, United \\ States
}

Venkat Nutalapati ${ }^{1}$, Vijay Kanakadandi², Madhav Desai ${ }^{2}$, Mojtaba Olyaee ${ }^{2}$, Amit Rastogi ${ }^{2}$

submitted 25.1.2018

accepted after revision 9.5.2018

\author{
Bibliography \\ DOI https://doi.org/10.1055/a-0650-4258 | \\ Endoscopy International Open 2018; 06: E1214-E1223 \\ (c) Georg Thieme Verlag KG Stuttgart · New York \\ ISSN 2364-3722
}

Corresponding author

Amit Rastogi, MD, Department of Gastroenterology \& Hepatology, University of Kansas Medical Center, 3901 Rainbow Blvd, Kansas City, KS 66160, USA arastogi@kumc.edu

\section{ABSTRACT}

Background and study aims Standard colonoscopy (SC) is the preferred modality for screening for colon cancer; however, it carries a significant polyp/adenoma miss rate. Cap-assisted colonoscopy (CC) has been shown to improve polyp/adenoma detection rate, decrease cecal intubation time and increase cecal intubation rate when compared to standard colonoscopy (SC). However, data on adenoma detection rate (ADR) are conflicting. The aim of this metaanalysis was to compare the performance of CC with SC for ADR among high-quality randomized controlled trials.

Patients and methods We performed an extensive literature search using MEDLINE, EMBASE, Scopus, Cochrane and Web of Science databases and abstracts published at national meetings. Only comparative studies between CC and SC were included if they reported ADR, adenoma per person (APP), cecal intubation rate, and cecal intubation time. The exclusion criterion for comparing ADR was studies with Jadad score $\leq 2$. The odds ratio (OR) was calculated using Mantel-Haenszel method. $P^{2}$ test was used to measure heterogeneity among studies.

Results Analysis of high-quality studies (Jadad score $\geq 3$, total of 7 studies) showed that use of cap improved the ADR with the results being statistically significant (OR $1.18,95 \% \mathrm{Cl} 1.03-1.33)$ and detection of $0.16(0.02-$ 0.30 ) additional APP. The cecal intubation rate in the CC group was $96.3 \%$ compared to $94.5 \%$ with SC (total of 17 studies). Use of cap improved cecal intubation (OR 1.61, $95 \% \mathrm{Cl} 1.33-1.95)$ when compared to SC $(P$ value $<0.001)$. Use of cap decreased cecal intubation time by an average of 0.88 minutes $(95 \% \mathrm{Cl} 0.37-1.39)$ or 53 seconds.

Conclusions Meta-analysis of high-quality studies showed that CC improved the ADR compared to SC.

\section{Introduction}

Population-based colorectal cancer (CRC) screening has been shown to reduce incidence of colon cancer and related mortality [1,2]. Among patients at average risk, the most favored cancer prevention test is colonoscopy every 10 years, beginning at age 50 (45 for African-Americans) [3]. Screening per 1000 patients using colonoscopy, a gain of 270 life-years and a decrease in 24 deaths from CRC has been estimated [4].

However, despite being the reference standard, colonoscopy is far from a perfect test. Studies using compute tomography colonography have estimated the sensitivity of colonoscopy for detecting advanced adenomas to be $88 \%$ [5]. Tandem colonoscopy studies have shown that up to one-quarter of polyps are missed during colonoscopy [6]. Adenoma detection rate (ADR) has been shown to be associated with interval colon cancer and related mortality $[7,8]$. ADR $\geq 30 \%$ for men and $\geq 20 \%$ for women has been recommended as a quality indicator for colonoscopy [9]. Wide variations in ADRs for endoscopists have been reported $[10,11]$. Therefore, various methods have been employed in attempts to improve ADR, including brief educational interventions [12], use of distal attachments such as caps [13], third-eye retroscopes, newer-generation wide-angle colonoscopes, cuffs and EndoRings. 
- Primary and secondary search

- 1473 records identified primarily

- 927 records identified secondarily

- 255 Pubmed, 394 Cinahl, 437 Scopus, 362 Embase, 25 Cochrane

- 708 DDW proceedings, 109 UEG proceedings, 110 records suggested by bibliography

- Initial Exclusion: Case reports, conference or symposium abstracts, review articles, editorials, duplicates

- 42 records after initial exclusion, 2558 records excluded

- 19 full text atricles were aseesed for eligibility

- 7 (score $\geq 3$ ) RCTs were used for analysis of ADR

- 17 studies were included for cecal intubation rate

- 13 studies were included for cecal intubation time

- Fig. 1 Study flow diagram depicting search strategy, screening and studies of cap-assisted colonoscopy identified for inclusion in the meta-analysis of adenoma detection rate.

Cap-assisted colonoscopy (CC) has been extensively studied as a modality to improve ADR. The cap is a straightforward attachment on the distal end of the endoscope that extends outward beyond the tip of tje colonoscope to varying lengths. The cap helps in deflecting and flattening the mucosal folds, and by keeping the mucosa away from the lens prevents a red-out. These maneuvers expose the proximal aspects of colonic folds and thereby help in detecting polyps in these otherwise blind mucosal areas. Use of cap has been shown to decrease cecal intubation time, increase cecal intubation rate and improve polyp detection rate. However, data on ADR are rather conflicting. The aim of this meta-analysis was to compare the performance of CC with standard colonoscopy (SC) for ADR among highquality randomized controlled trials (RCT).

\section{Patients and methods}

\section{Search strategy}

An electronic search was performed in MEDLINE, EMBASE, Google scholar, Cochrane database and Web of science. The search for studies of relevance was performed using the following key words and corresponding Medical Subject Heading/Entree terms when possible: "CAP assisted colonoscopy," "colonoscopy with distal attachment," "adenoma detection rate," "adenoma per person," "cecal intubation rate," "cecal intubation time" with varying combinations with and/or. We retrieved 2558 abstracts (\$ Fig. 1). Abstracts published in major international conferences, including Digestive Disease Week, United Europe-
- Table 1 Studies and their respective Jadad scores.

\begin{tabular}{|c|c|c|}
\hline Study & & Final score \\
\hline Tada 1997 & Paper & 0 \\
\hline Matsushita 1998 & Paper & 1 \\
\hline Kondo 2007 & Paper & 3 (No ADR/APP reported) \\
\hline Horiuchi 2008 & Paper & 3 \\
\hline Shida 2008 & Paper & 0 \\
\hline Takano 2008 & Abstract & 0 \\
\hline Lee 2009 & Paper & 1 \\
\hline Choi 2009 & Paper & 0 \\
\hline Harada 2009 & Paper & 1 \\
\hline Sato 2009 & $\begin{array}{l}\text { Prelim } \\
\text { Report }\end{array}$ & 3 (No ADR/APP reported) \\
\hline Takeuchi 2010 & Paper & 3 \\
\hline Tee 2010 & Paper & 3 (No ADR/APP reported) \\
\hline Dai 2010 & Paper & 0 \\
\hline Hewett 2010 & Paper & 3 \\
\hline Park 2012 & Paper & 3 \\
\hline Rastogi 2012 & Paper & 3 \\
\hline De Wijkerslooth 2012 & Paper & 4 \\
\hline Frieling 2013 & Paper & 3 (No ADR/APP reported) \\
\hline Pohl 2015 & Paper & 3 \\
\hline
\end{tabular}

an Gastroenterology Week and Asia Pacific Digestive Week over the past 10 years were manually searched. References from major trials and review articles were manually searched.

From the 2400 records, 2358 records were removed (1473 studies, 927 abstracts) because they were not relevant to the comparison between CC and SC. Of the remaining 42 records, 23 were excluded for the following reasons: duplicity, case report, review article, editorial, abstract only. Of the 19 full-text articles that were accepted, only 7 met the criteria of prospective RCTs, Jadad score $\geq 3$ (see $>$ Table 1 ), reported ADR, and these studies were used for ADR and APP (adenomas detected per person) [14-20]. Of the 42 records, 17 studies were included that compared cecal intubation rate between CC and SC [14-30]. Thirteen studies were included that compared cecal intubation time between CC and SC [14-17,19,21-23,25, $26,30-32]$. For analysis of cecal intubation and cecal intubation time, even studies with Jadad score $<3$ were included. ADR alone was the primary aim of the study. We removed the constraints for cecal intubation time or rate as we wanted to be less stringent and more inclusive for these endpoints. While $A D R$ is a cornerstone quality indicator for colonoscopy, the other two are not. 
- Table 2 Study characteristics.

\begin{tabular}{|c|c|c|c|c|c|c|}
\hline Author & Country & Sample & CC & SC & Age & Male (\%) \\
\hline Tada et al. [32] & Japan & 140 & 70 & 70 & 60 & 73 \\
\hline Matsushita et al. [26] & Japan & 24 & 12 & 12 & 59 & 63 \\
\hline Kondo et al. [24] & Japan & 456 & 221 & 235 & 61 & 60 \\
\hline Horiuchi et al. [16] & Japan & 835 & 424 & 411 & 64 & 65 \\
\hline Shida et al. [28] & Japan & 178 & 82 & 96 & 64 & 51 \\
\hline Takano et al. [29] & Japan & 2502 & 1287 & 1215 & NA & NA \\
\hline Harada et al. [23] & Japan & 592 & 289 & 303 & 63 & 66 \\
\hline Lee et al. [25] & Hong Kong & 1000 & 499 & 501 & 53 & 46 \\
\hline Sato et al. [27] & Japan & 221 & 110 & 111 & NA & NA \\
\hline Dai et al. [31] & China & 250 & 121 & 129 & 51 & 54 \\
\hline Hewett et al. [15] & United States & 100 & 52 & 48 & 62 & 57 \\
\hline Takeuchi et al. [20] & Japan & 274 & 141 & 133 & 64 & 70 \\
\hline Tee et al. [30] & Australia & 400 & 200 & 200 & 54 & 48 \\
\hline De Wijkerslooth et al. [14] & Netherlands & 1339 & 656 & 683 & 60 & 51 \\
\hline Choi et al. [21] & Korea & 228 & 114 & 114 & NA & NA \\
\hline Rastogi et al. [19] & United States & 420 & 210 & 210 & 61 & 95 \\
\hline Park et al. [17] & Korea & 600 & 300 & 300 & 62 & 52 \\
\hline Frieling et al. [22] & Germany & 504 & 252 & 252 & $60 \pm 15.5$ & 182 \\
\hline Pohl et al. [18] & United States & 1113 & 562 & 551 & 62 & 64 \\
\hline
\end{tabular}

\section{Data extraction}

Two investigators (VN and MD) independently reviewed the studies and imported the data into a standardized form. In case of lack of consensus, the senior investigator (AR) reviewed the study independently and then made a final decision regarding the data point.

Data extracted were patient demographics, year of publication, study location, number of subjects, size of adenomas, number of adenomas detected, cecal intubation rate, cecal intubation time and study quality. Individual study and patient characteristics are shown in $>$ Table 2.

\section{Statistical analysis}

Meta-analyses were performed using Mantel-Haenszel method combining the results from different trials comparing $C C$ and SC. Meta-Analysis was performed according to the PRISMA statement. A complete checklist is provided in > Table 3 [33]. A random effects model was used for statistical heterogeneity across trials and a fixed effect model was used if no significant heterogeneity was present. Relative risks (RR) with corresponding $95 \% \mathrm{Cl}$ were calculated. Heterogeneity was calculated using $1^{2}$ test. Publication bias was assessed using a funnel plot. Statistical analyses were performed using RevMan software (Review Manager version 5.3; The Nordic Cochrane Centre, Copenhagen, Demark, The Cochrane Collaboration 2015).

\section{Results}

\section{Adenoma detection rate}

An initial pooled analysis of eight RCTs (5681 patients) was performed, which showed a numerically higher ADR in the CC group compared to the SC group, but results were not statistically significant (OR 1.08, 95\% Cl 0.97-1.21; $\mathrm{I}^{2}$ 56\%) (> Fig. 2a). However, when only high-quality RCTs were included (Jadad score $\geq 3$ ) as per the primary aim of this study, there were seven RCTs with a total of 4,681 patients (2,344 patients in the CC group, 2,337 patients in the SC group). We were unbale to include some studies with a score of 3 or more, as they lacked information regarding ADR/APP $[22,24,30]$. ADR was significantly higher in the CC group (OR 1.18, 95\% Cl 1.03-1.33) ( $\triangleright$ Fig.2b). There was no significant heterogeneity in the ADR analysis $\left(I^{2}=0 \%\right)$. Publication bias for studies included for ADR was assessed using a funnel plot ( $\mathbf{F i g . 3}$ ).

Analysis was also performed using a random effects model. Analysis of the seven high-quality RCTs using the random effects model showed significantly higher ADR in the CC group (OR 1.104, $95 \% \mathrm{Cl} 1.02-1.18$ ) ( Fig. 2c).

Sensitivity analysis was not performed based on our stringent criteria to include only high-quality studies with Jadad score $\geq 3$ which carry a very low risk for bias [34-36]. 
- Table 3 PRISMA checklist.

TITLE

\begin{tabular}{|c|c|c|c|}
\hline Title & 1 & Identify the report as a systematic review, meta-analysis, or both. & $\begin{array}{l}\text { Mentioned as meta- } \\
\text { analysis }\end{array}$ \\
\hline \multicolumn{4}{|l|}{ ABSTRACT } \\
\hline Structured summary & 2 & $\begin{array}{l}\text { Provide a structured summary including, as applicable: background; objectives; data } \\
\text { sources; study eligibility criteria, participants, and interventions; study appraisal and } \\
\text { synthesis methods; results; limitations; conclusions and implications of key findings; } \\
\text { systematic review registration number: }\end{array}$ & $\begin{array}{l}\text { A detailed abstract } \\
\text { with the necessary } \\
\text { information has been } \\
\text { provided }\end{array}$ \\
\hline \multicolumn{4}{|l|}{ INTRODUCTION } \\
\hline Rationale/ & 3 & Describe the rationale for the review in the context of what is already known. & Provided \\
\hline Objectives & 4 & $\begin{array}{l}\text { Provide an explicit statement of questions being addressed with reference to partici- } \\
\text { pants, interventions, comparisons, outcomes, and study design (PICOS). }\end{array}$ & Provided \\
\hline \multicolumn{4}{|l|}{ METHODS } \\
\hline $\begin{array}{l}\text { Protocol and } \\
\text { registration/ }\end{array}$ & 5 & $\begin{array}{l}\text { Indicate if a review protocol exists, if and where it can be accessed (e. g., Web ad- } \\
\text { dress), and, if available, provide registration information including registration num- } \\
\text { ber. }\end{array}$ & $\begin{array}{l}\text { Not applicable with } \\
\text { Meta-analysis }\end{array}$ \\
\hline Eligibility criteria & 6 & $\begin{array}{l}\text { Specify study characteristics (e. g., PICOS, length of follow-up) and report character- } \\
\text { istics (e. g., years considered, language, publication status) used as criteria for elig- } \\
\text { ibility, giving rationale. }\end{array}$ & Provided \\
\hline Information sources & 7 & $\begin{array}{l}\text { Describe all information sources (e. g., databases with dates of coverage, contact with } \\
\text { study authors to identify additional studies) in the search and date last searched. }\end{array}$ & Provided \\
\hline Search & 8 & $\begin{array}{l}\text { Present full electronic search strategy for at least one database, including any limits } \\
\text { used, such that it could be repeated. }\end{array}$ & Provided \\
\hline Study selection & 9 & $\begin{array}{l}\text { State the process for selecting studies (i. e., screening, eligibility, included in sys- } \\
\text { tematic review, and, if applicable, included in the meta-analysis). }\end{array}$ & Provided \\
\hline $\begin{array}{l}\text { Data collection } \\
\text { process }\end{array}$ & 10 & $\begin{array}{l}\text { Describe method of data extraction from reports (e. g., piloted forms, independently, } \\
\text { in duplicate) and any processes for obtaining and confirming data from investigators. }\end{array}$ & Provided \\
\hline Data items & 11 & $\begin{array}{l}\text { List and define all variables for which data were sought (e. g., PICOS, funding sources) } \\
\text { and any assumptions and simplifications made. }\end{array}$ & Provided \\
\hline $\begin{array}{l}\text { Risk of bias in } \\
\text { individual studies }\end{array}$ & 12 & $\begin{array}{l}\text { Describe methods used for assessing risk of bias of individual studies (including spe- } \\
\text { cification of whether this was done at the study or outcome level), and how this in- } \\
\text { formation is to be used in any data synthesis. }\end{array}$ & Provided \\
\hline Summary measures & 13 & State the principal summary measures (e. g., risk ratio, difference in means). & Provided \\
\hline Synthesis of results & 14 & $\begin{array}{l}\text { Describe the methods of handling data and combining results of studies, if done, } \\
\text { including measures of consistency }\left(\text { e. g., } I^{2}\right) \text { for each meta-analysis. }\end{array}$ & Provided \\
\hline $\begin{array}{l}\text { Risk of bias across } \\
\text { studies }\end{array}$ & 15 & $\begin{array}{l}\text { Specify any assessment of risk of bias that may affect the cumulative evidence } \\
\text { (e. g., publication bias, selective reporting within studies). }\end{array}$ & Provided \\
\hline Additional analyses & 16 & $\begin{array}{l}\text { Describe methods of additional analyses (e.g., sensitivity or subgroup analyses, } \\
\text { meta-regression), if done, indicating which were pre-specified. }\end{array}$ & Provided \\
\hline \multicolumn{4}{|l|}{ RESULTS } \\
\hline Study selection & 17 & $\begin{array}{l}\text { Give numbers of studies screened, assessed for eligibility, and included in the review, } \\
\text { with reasons for exclusions at each stage, ideally with a flow diagram. }\end{array}$ & Provided \\
\hline Study characteristics & 18 & $\begin{array}{l}\text { For each study, present characteristics for which data were extracted (e. g., study size, } \\
\text { PICOS, follow-up period) and provide the citations. }\end{array}$ & Provided \\
\hline $\begin{array}{l}\text { Risk of bias within } \\
\text { studies }\end{array}$ & 19 & $\begin{array}{l}\text { Present data on risk of bias of each study and, if available, any outcome-level assess- } \\
\text { ment (see Item 12). }\end{array}$ & Provided \\
\hline $\begin{array}{l}\text { Results of individual } \\
\text { studies }\end{array}$ & 20 & $\begin{array}{l}\text { For all outcomes considered (benefits or harms), present, for each study: (a) simple } \\
\text { summary data for each intervention group and (b) effect estimates and confidence } \\
\text { intervals, ideally with a forest plot. }\end{array}$ & Provided \\
\hline
\end{tabular}




\begin{tabular}{|c|c|c|c|}
\hline Synthesis of results & 21 & $\begin{array}{l}\text { Present results of each meta-analysis done, including confidence intervals and meas- } \\
\text { ures of consistency. }\end{array}$ & Provided \\
\hline $\begin{array}{l}\text { Risk of bias across } \\
\text { studies }\end{array}$ & 22 & Present results of any assessment of risk of bias across studies (see Item 15). & Provided \\
\hline Additional analysis & 23 & $\begin{array}{l}\text { Give results of additional analyses, if done (e. g., sensitivity or subgroup analyses, } \\
\text { meta-regression [see Item 16]). }\end{array}$ & Provided \\
\hline \multicolumn{4}{|l|}{ DISCUSSION } \\
\hline Summary of evidence & 24 & $\begin{array}{l}\text { Summarize the main findings including the strength of evidence for each main out- } \\
\text { come; consider their relevance to key groups (e. g., health care providers, users, and } \\
\text { policy makers). }\end{array}$ & Provided \\
\hline Limitations & 25 & $\begin{array}{l}\text { Discuss limitations at study and outcome level (e. g., risk of bias), and at review level } \\
\text { (e. g., incomplete retrieval of identified research, reporting bias). }\end{array}$ & Provided \\
\hline Conclusions & 26 & $\begin{array}{l}\text { Provide a general interpretation of the results in the context of other evidence, and } \\
\text { implications for future research. }\end{array}$ & Provided \\
\hline \multicolumn{4}{|l|}{ FUNDING } \\
\hline Funding & 27 & $\begin{array}{l}\text { Describe sources of funding for the systematic review and other support (e. g., supply } \\
\text { of data); role of funders for the systematic review }\end{array}$ & Provided \\
\hline
\end{tabular}

\section{Mean adenomas detected per person}

Analysis for APP included six RCTs with 4,368 patients. There were 2184 patients in each group. Use of cap led to a mean difference of $0.16(95 \% \mathrm{Cl} 0.02-0.30)$ additional APP ( $\mathbf{F i g} .4)$. Significant heterogeneity was found in the studies reporting mean $\operatorname{APP}\left(I^{2}=68 \%\right)$.

\section{Large adenoma detection rate}

Analysis for large adenomas ( $\geq 10 \mathrm{~mm}$ ) included four RCTs with 2468 patients. There were 1247 patients in the CC group compared to 1221 patients in the SC group. Use of cap led to a statistically significantly higher rate of detection of large adenomas (OR 1.49, $95 \% \mathrm{Cl} 1.03-2.15, P<0.005)$ with heterogeneity of $\left(I^{2}=44 \%\right)$ ( Fig. 5$)$.

\section{Sessile serrated adenoma detection rate}

Analysis for sessile serrated adenoma (SSA) included only three RCTs with 2872 patients. There were 1427 patients in the CC group compared to 1445 patients in the SC group. Use of cap did not lead to any significant difference in detection of SSA with (OR 1.12, $95 \% \mathrm{Cl} 0.66-1.88$ ) and a significant heterogeneity of $\left(I^{2}=76 \%\right)$ ( $>$ Fig. 6$)$.

\section{Cecal intubation rate and time}

Pooled analysis of 17 studies that included 5416 patients in the CC and 5401 patients in the SC groups were utilized to evaluate the cecal intubation rate ( $\mathbf{F i g . 7 a ) . ~ T h e ~ c e c a l ~ i n t u b a t i o n ~ r a t e ~ i n ~}$ the CC group was $96.3 \%$ compared to $94.5 \%$ with SC. Use of cap improved cecal intubation (OR 1.61, $95 \% \mathrm{Cl} 1.33-1.95)$ when compared to SC $(P<0.001)$. Low heterogeneity was identified among studies $\left(I^{2}=2 \%\right)$.

Thirteen studies were used to analyze the impact of cap on cecal intubation time ( $\triangleright$ Fig. 7b). The CC group included 3014 patients and the SC group included 3037 patients. Use of cap decreased the cecal intubation time by an average of $0.88 \mathrm{~min}$ - utes ( $95 \% \mathrm{Cl} 0.37-1.39$ ) or 53 seconds. However, significant heterogeneity was detected among these studies $\left(R^{2}=87 \%\right)$.

\section{Discussion}

Results of our meta-analysis indicate that use of cap improves detection of adenomas. An improvement in ADR, mean number of adenomas detected per patient and large adenomas was seen with CC. For ADR we included only trials with a Jadad score $\geq 3$ to ensure only high-quality trials. The Jadad score is the most widely used scale to measure the quality of RCTs. Overall, we found seven RCTs with a Jadad score $\geq 3$. This study differs from a previous meta-analysis [13] in that we excluded the study by Lee [25] as it employed suboptimal techniques for randomization. Proper technique includes a statistician and computer-generated randomization, where as in the study by Lee et al, only sealed envelopes were used without mention of statistician or a computer-generated sequence [25]. Furthermore, in that study, the quality of bowel preparation was significantly less satisfactory. They classified the quality of their bowel preparation into three categories: "excellent," "fair," and "poor." In the results, they noted that a higher proportion of patients in the CC group had less satisfactory bowel preparation (excellent/fair/poor bowel preparation in CC group were 52.7:33.5:13.8\% vs. SC group's 62.3:28.1:9.6\%, respectively, $P$ $=0.006)$. They also reported an ADR that was lower with use of CAP. The inferior bowel preparation in the CC group could have negatively impacted the ADR. As a matter of fact, this is the only trial where use of CAP has been associated with lower ADR compared to standard colonoscopy. All other trials have shown either no difference or higher ADR with CAP.

$A D R$ is a quality indicator for colonoscopy and has been shown to be associated with improved outcomes related to interval cancer and colorectal cancer-related mortality. While this meta-analysis shows an overall improvement in ADR with CC, individual studies have shown variable results. The study 


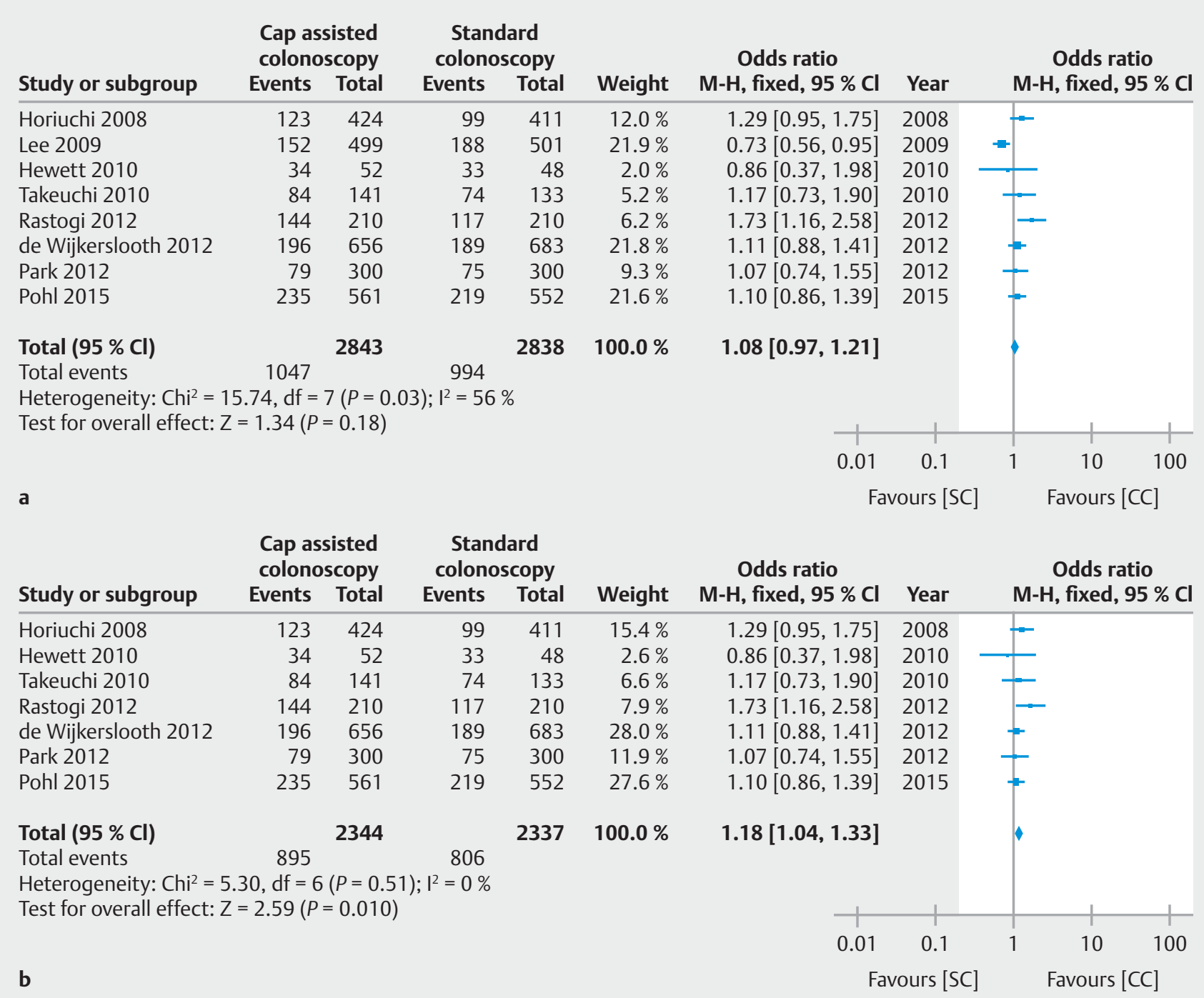

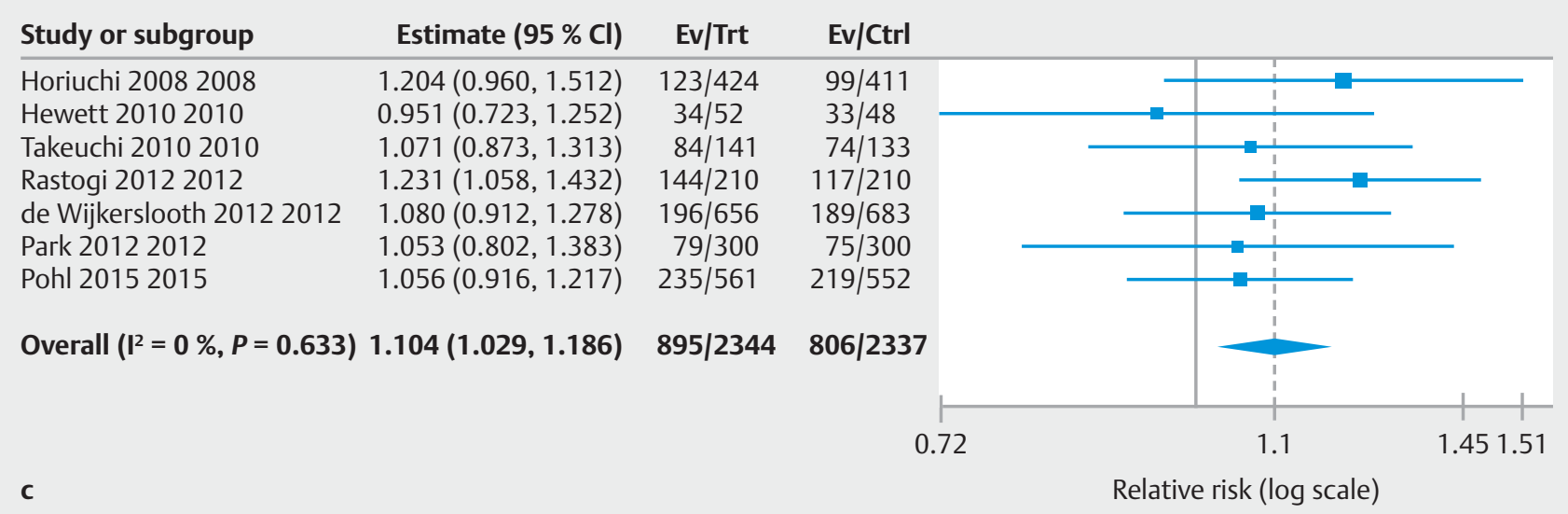

- Fig. 2 Forest plot of pooled estimates of adenoma detection rate using cap-assisted colonoscopy compared to standard colonoscopy. a Results with all eligible studies. b Results with only high-quality studies (Jadad score $\geq 3$ ). c Results with only high-quality studies using random effects.

by Pohl et al. [18] which was the largest study evaluating CC in the United States showed that the impact on the individual endoscopist ADR is variable. The range of impact was from
$20 \%$ improvement to $15 \%$ decrease in the individual ADR with CC. They also showed that those who preferred 


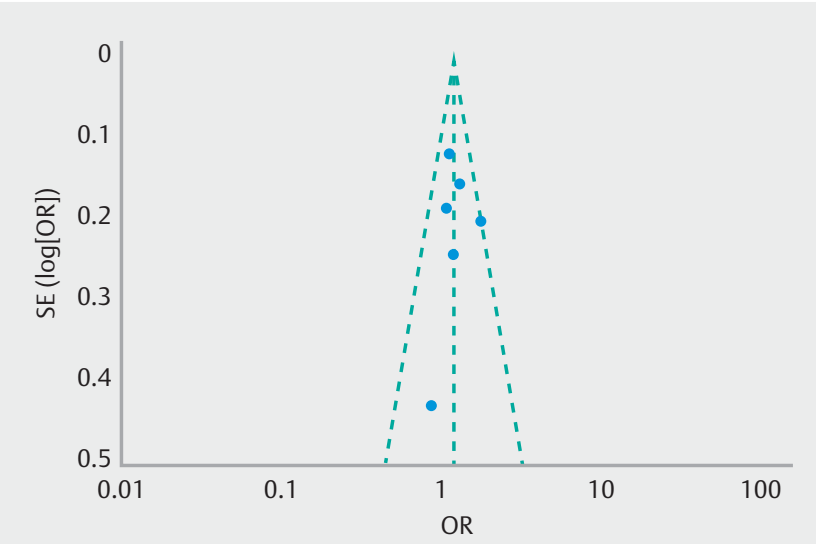

Fig. 3 Funnel plot showing publication bias.
CAP showed an improvement in ADR. We have also shown an improvement in the average number of adenomas detected per patient.

CC also improved detection of large adenomas, however, a statistically significant improvement in mean number of diminutive adenomas was not found. We suspect this may be due, in part, to the differing sizes of small adenomas reported ( $5 \mathrm{~mm}$ vs. $6 \mathrm{~mm})$. There was no significant improvement in detection of proximal adenomas or SSAs as the RCTs that were performed were not adequately powered to detect any difference in the above outcomes.

Our meta-analysis has some limitations. The study populations in the studies were very diverse with studies being performed in Asia, North America, and Europe. That, however, improves generalizability of the results. Given the obvious lack of blinding of the endoscopists and the nature of such studies evaluating devices to improve ADR, investigator bias is unavoidable. Endoscopist experience in the different studies also varies widely and could not be accounted for with respect to

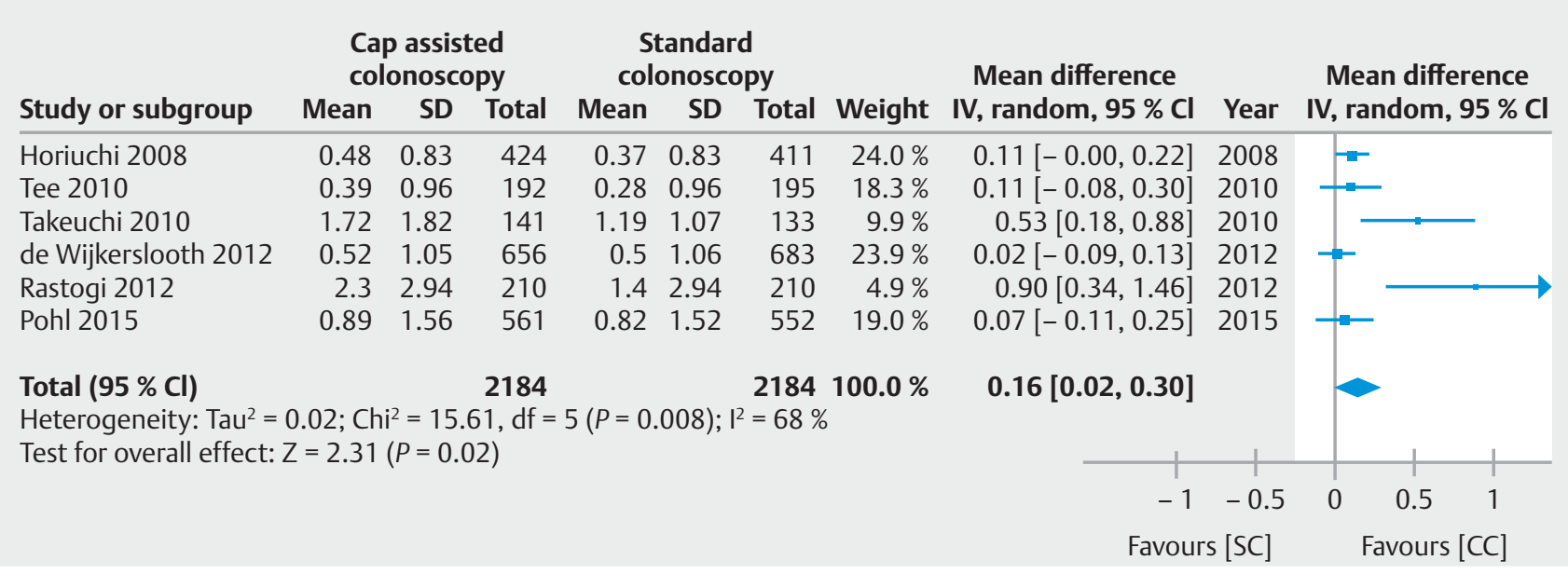

Fig. 4 Forest plot of pooled estimate of adenoma per person (APP) showing higher detection of average adenoma per person using cap compared to standard colonoscopy.

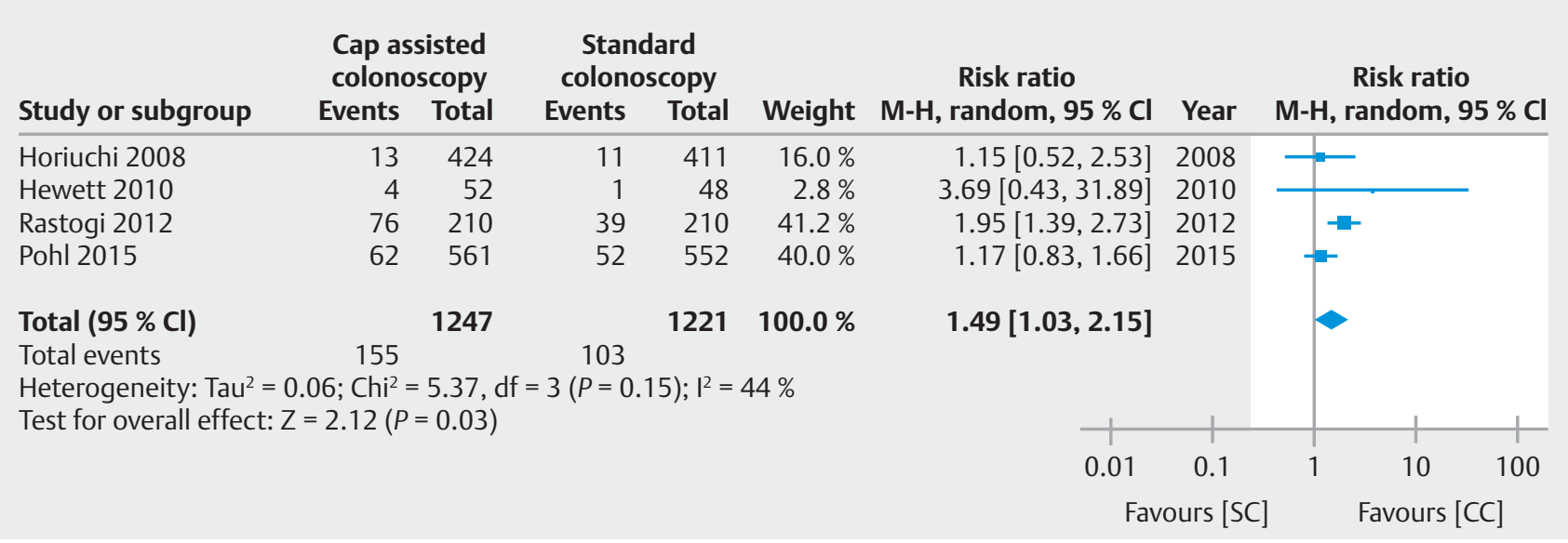

Fig. 5 Figure plot of pooled estimate of adenomas $>10 \mathrm{~mm}$, showing significant improved detection with CAP assisted colonoscopy compared to standard colonoscopy 


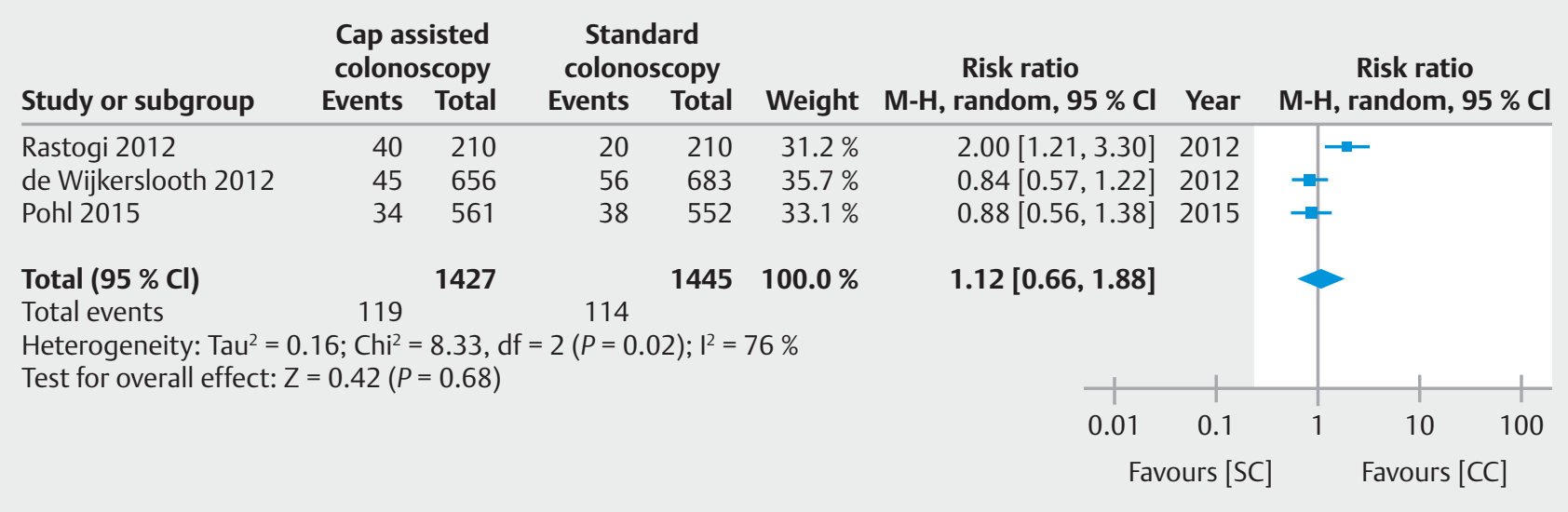

- Fig. 6 Figure plot of pooled estimate of sessile serrated adenoma (SSA) showing no significant improvement in the detection of proximal adenomas.

the impact of CC on ADR. Use of a cap with colonoscopy requires some training, adjustment, and experience. This factor was not adjusted for or studied in the trials, making it difficult to gauge the impact of that on the results.

A cap is a simple, inexpensive and easy-to-use tool to improve the quality of colonoscopy. The cost of the cap, albeit low, appears to be the only negative factor weighing against its use in daily clinical practice. To derive maximum benefit from cap, endoscopists need to gain experience with the device. As the cap projects outside the tip of the colonoscope, it may appear to limit the angle of view. This must be compensated for withi adequate deflection of the tip and use of the edge of the cap to flatten the haustral folds to expose their proximal aspects and derive the maximum benefit. Furthermore, the benefit of CC has been shown to significantly extend visualization of the right colon in a colonoscopic training model [37]. Use of cap offers other secondary benefits such as improved cecal intubation rates and stabilization of the tip of the scope during polypectomy.

\section{Conclusion}

In conclusion, this meta-analysis showed that there is a marginal and statistically significant benefit to use of a cap during colonoscopy to improve ADR and cecal intubation rate and reduce cecal intubation time. Further research needs to be conducted to determine if there are specific patient subgroups that may benefit more from use of a cap, whether to train endoscopists in use of the device, and identify appropriate training methods.

\section{Competing interest}

None

\section{References}

[1] Winawer S], Zauber AG, Ho MN. The National Polyp Study Workgroup. et al. Prevention of colorectal cancer by colonoscopic polypectomy. N Engl J Med 1993; 329: 1977 -1981

[2] Nishihara R, Wu K, Lochhead P et al. Long-term colorectal-cancer incidence and mortality after lower endoscopy. N Engl J Med 2013; 369: $1095-1105$

[3] Rex DK, Johnson DA, Anderson JC et al. American College of Gastroenterology guidelines for colorectal cancer screening 2009 [corrected]. Am J Gastroenterol 2009; 104: 739-750

[4] Draft Recommendation Statement: Colorectal Cancer. Screening. U.S. Preventive Services Task Force 2015: Available from: http:// www.uspreventiveservicestaskforce.org/Page/Document/draft-recommendation-statement38/colorectal-cancer-screening2 [cited 2015 October 9th]

[5] Pickhardt P], Choi JR, Hwang I et al. Computed tomographic virtual colonoscopy to screen for colorectal neoplasia in asymptomatic adults. N Engl J Med 2003; 349: 2191 - 2200

[6] van Rijn JC, Reitsma JB, Stoker J et al. Polyp miss rate determined by tandem colonoscopy: a systematic review. Am J Gastroenterol 2006; 101: $343-350$

[7] Kaminski MF, Regula J, Kraszewska E et al. Quality indicators for colonoscopy and the risk of interval cancer. N Engl J Med 2010; 362: $1795-1803$

[8] Corley DA, Jensen CD, Marks AR et al. Adenoma detection rate and risk of colorectal cancer and death. N Engl J Med 2014; 370: 1298 1306

[9] Rex DK, Schoenfeld PS, Cohen J et al. Quality indicators for colonoscopy. Gastrointest Endosc 2015; 81: 31 - 53

[10] Barclay RL, Vicari J], Greenlaw RL. Effect of a time-dependent colonoscopic withdrawal protocol on adenoma detection during screening colonoscopy. Clin Gastroenterol Hepatol 2008; 6: 1091 - 1098

[11] Sawhney MS, Cury MS, Neeman N et al. Effect of institution-wide policy of colonoscopy withdrawal time $>$ or $=7$ minutes on polyp detection. Gastroenterology 2008; 135: $1892-1898$

[12] Coe SG, Crook JE, Diehl NN et al. An endoscopic quality improvement program improves detection of colorectal adenomas. Am J Gastroenterol 2013; 108: 219-226; quiz 227

[13] Ng SC, Tsoi KK, Hirai HW et al. The efficacy of cap-assisted colonoscopy in polyp detection and cecal intubation: a meta-analysis of randomized controlled trials. Am J Gastroenterol 2012; 107: 1165-1173 


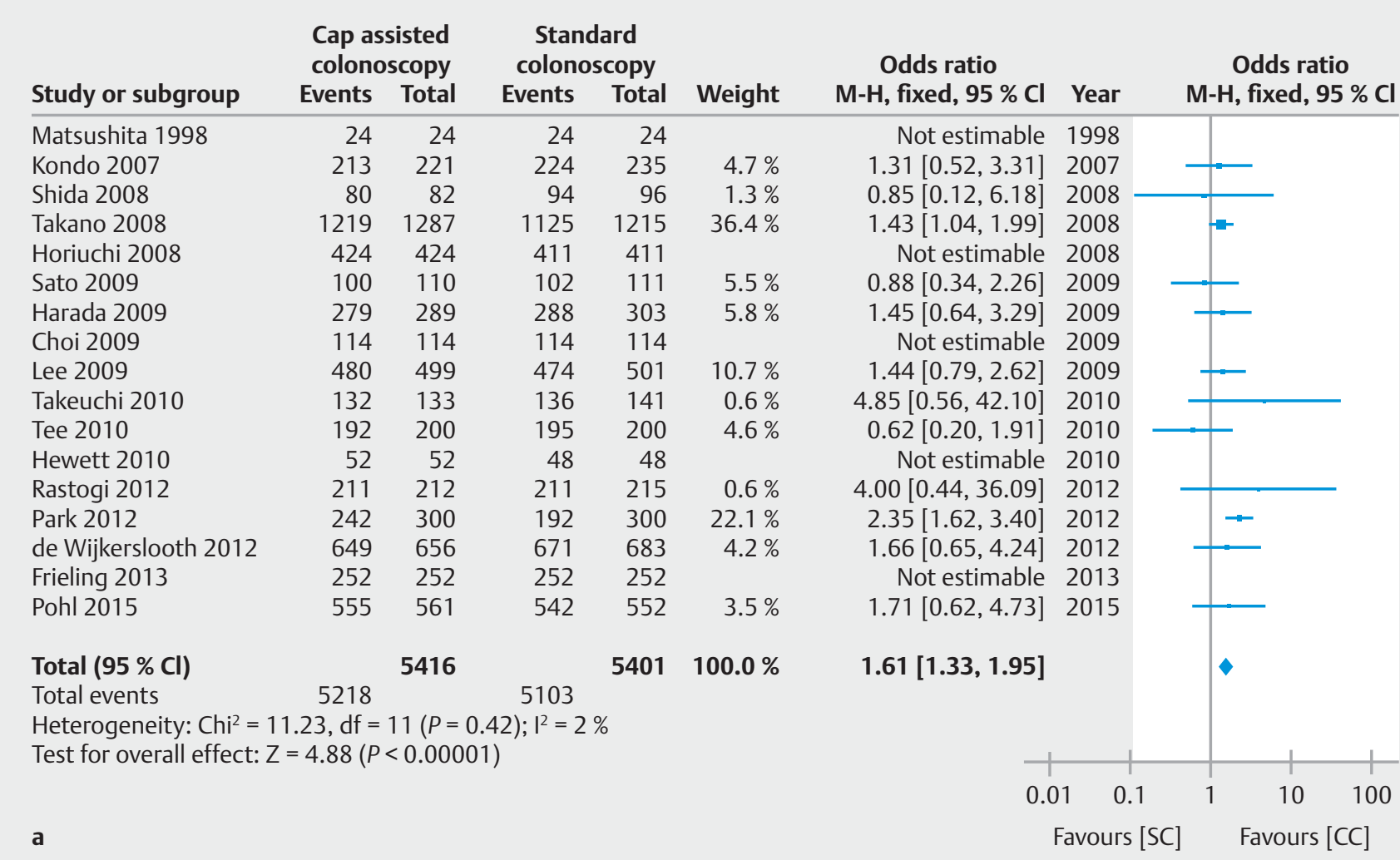

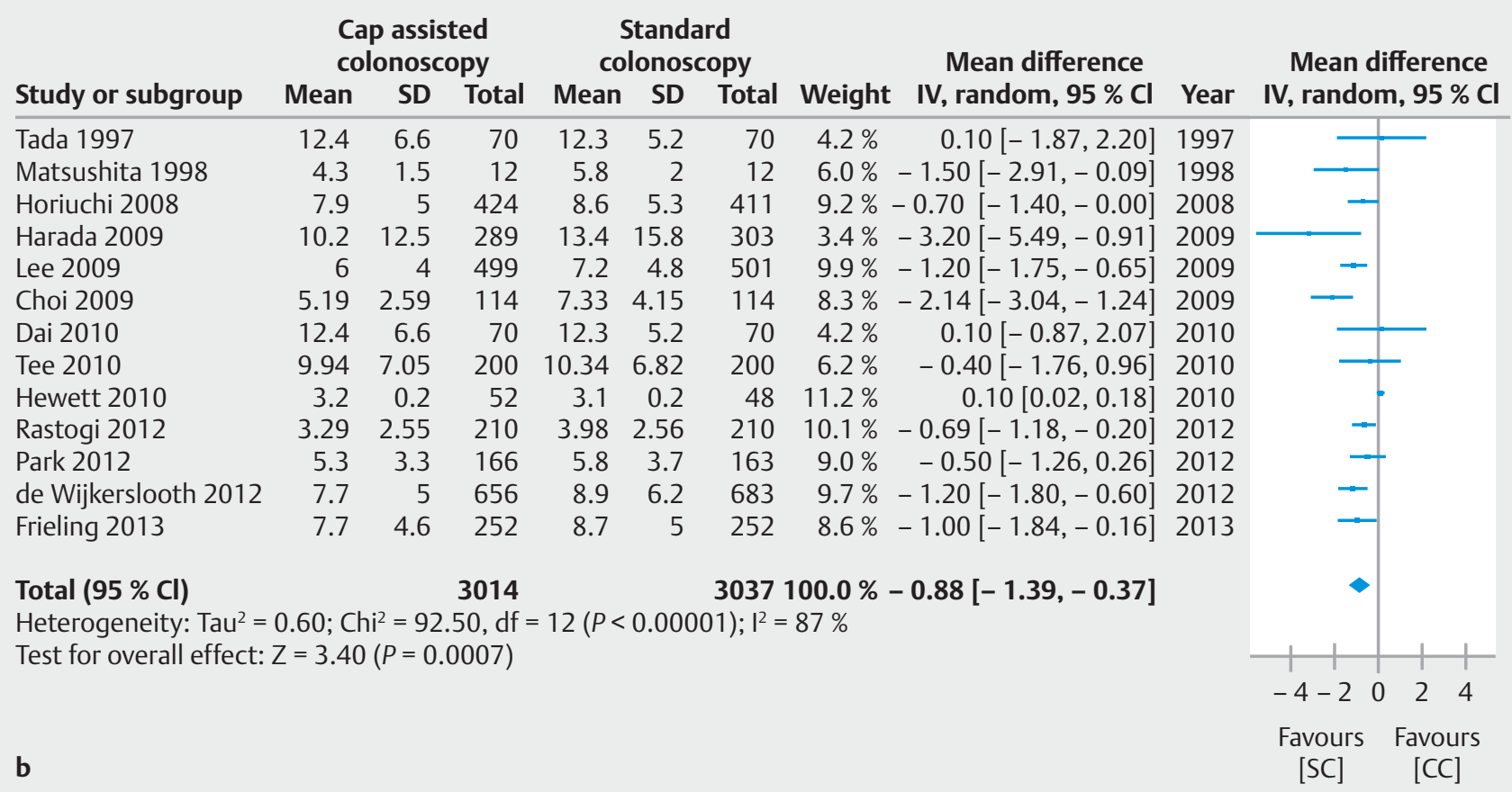

Fig.7 Forest plot of pooled estimates of cecal intubation rate (a) and cecal intubation time (b) showing improved rates and lesser time with cap compared to standard colonoscopy 
[14] de Wijkerslooth TR, Stoop EM, Bossuyt PM et al. Adenoma detection with cap-assisted colonoscopy versus regular colonoscopy: a randomised controlled trial. Gut 2012; 61: $1426-1434$

[15] Hewett DG, Rex DK. Cap-fitted colonoscopy: a randomized, tandem colonoscopy study of adenoma miss rates. Gastrointest Endosc 2010; 72: $775-781$

[16] Horiuchi A, Nakayama Y. Improved colorectal adenoma detection with a transparent retractable extension device. Am J Gastroenterol 2008; 103: $341-345$

[17] Park SM, Lee SH, Shin KY et al. The cap-assisted technique enhances colonoscopy training: prospective randomized study of six trainees. Surg Endosc 2012; 26: 2939-2943

[18] Pohl H, Bensen SP, Toor A et al. Cap-assisted colonoscopy and detection of adenomatous polyps (AP) study: a randomized trial. Endoscopy 2015; 47: $891-897$

[19] Rastogi A, Bansal A, Rao DS et al. Higher adenoma detection rates with cap-assisted colonoscopy: a randomised controlled trial. Gut 2012; 61: 402-408

[20] Takeuchi Y, Inoue T, Hanaoka N et al. Autofluorescence imaging with a transparent hood for detection of colorectal neoplasms: a prospective, randomized trial. Gastrointest Endosc 2010; 72: 1006-1113

[21] Choi DH, Shin HK, Lee YS et al. Efficacy of transparent cap-attached colonoscopy: does it improve the quality of colonoscopy? J Korean Soc Coloproctol 2010; 26: $16-122$

[22] Frieling T, Neuhaus F, Kuhlbusch-Zicklam R et al. Prospective and randomized study to evaluate the clinical impact of cap assisted colonoscopy (CAC). Z Gastroenterol 2013; 51: 1383-1388

[23] Harada Y, Hirasawa D, Fujita $\mathrm{N}$ et al. Impact of a transparent hood on the performance of total colonoscopy: a randomized controlled trial. Gastrointest Endosc 2009; 69: 637-644

[24] Kondo S, Yamaji Y, Watabe $\mathrm{H}$ et al. A randomized controlled trial evaluating the usefulness of a transparent hood attached to the tip of the colonoscope. Am J Gastroenterol 2007; 102: 75-81

[25] Lee YT, Lai LH, Hui AJ et al. Efficacy of cap-assisted colonoscopy in comparison with regular colonoscopy: a randomized controlled trial. Am J Gastroenterol 2009; 104: 41-46
[26] Matsushita M, Hajiro K, Okazaki K et al. Efficacy of total colonoscopy with a transparent cap in comparison with colonoscopy without the cap. Endoscopy 1998; 30: $444-447$

[27] Sato KHK, Hirahata K, Furuhata T. Efficacy of oblique transparent cap with colonoscope for trainees analyzed with magnetic endoscope imaging (MEI): a preliminary report. Gastrointest Endosc 2009; 69: AB120

[28] Shida T, Takano S, Kaiho M et al. Transparent hood attached to a gastroscope: a simple rescue technique for patients with difficult or incomplete colonoscopy. Endoscopy 2008; 40: E139

[29] Takano NYY, Yamaji Y, Kajiwara H. A randomized controlled trial of the usefulness of cap-fitted colonoscopy on the polyp detection. Gastrointest Endosc 2008: Japan

[30] Tee HP, Corte C, Al-Ghamd H et al. Prospective randomized controlled trial evaluating cap-assisted colonoscopy vs standard colonoscopy. World J Gastroenterol 2010; 16: 3905-3910

[31] Dai J, Feng N, Lu H et al. Transparent cap improves patients' tolerance of colonoscopy and shortens examination time by inexperienced endoscopists. J Dig Dis 2010; 11: $364-368$

[32] Tada M, Inoue H, Yabata E et al. Feasibility of the transparent cap-fitted colonoscope for screening and mucosal resection. Dis Colon Rectum 1997; 40: 618-621

[33] Moher D, Liberati A, Tetzlaff J et al. Preferred reporting items for systematic reviews and meta-analyses: the PRISMA statement. J Clin Epidemiol 2009; 62: $1006-1112$

[34] Khor BH, Narayanan SS, Sahathevan S et al. Efficacy of nutritional interventions on inflammatory markers in haemodialysis patients: a systematic review and limited meta-analysis. Nutrients 2018; 10: 397

[35] Hurley ET, Lim FD, Moran C] et al. The efficacy of platelet-rich plasma and platelet-rich fibrin in arthroscopic rotator cuff repair: a meta-analysis of randomized controlled trials. Am J Sports Med 2018; 10: 363546517751397

[36] Jadad AR, Moore RA, Carroll D et al. Assessing the quality of reports of randomized clinical trials: is blinding necessary? Control Clin Trials 1996; 17: $1-12$

[37] Frieling T, Neuhaus F, Heise J et al. Cap-assisted colonoscopy (CAC) significantly extends visualization in the right colon. Z Gastroenterol 2012; 50: $279-284$ 